Fernando Aith ${ }^{1,3}$

Yasmim Bujdoso ${ }^{2,3}$

Paulo Roberto do Nascimento ${ }^{3}$

Sueli Gandolfi Dallari ${ }^{2,3}$

\title{
OS PRINCÍPIOS DA UNIVERSALIDADE E INTEGRALIDADE DO SUS SOB A PERSPECTIVA DA POLÍTICA DE DOENÇAS RARAS E DA INCORPORAÇÃO TECNOLÓGICA
}

The principles of universality and integrality of the Brazilian National Public Health System from the perspective of the policy for rare diseases and the incorporation of technological resources

\footnotetext{
${ }^{1}$ Faculdade de Medicina, Universidade de São Paulo. São Paulo/SP, Brasil.

${ }^{2}$ Faculdade de Saúde Pública, Universidade de São Paulo. São Paulo/SP, Brasil.

${ }^{3}$ Núcleo de Pesquisa em Direito Sanitário da Universidade de São Paulo. São Paulo/ SP, Brasil.
}

Correspondência: Fernando Aith. E-mail: fernando.aith@usp.br.

Recebido em: 28/10/2012. Revisado em: 23/02/2013. Aprovado em: 15/04/2013. 


\section{RESUMO}

$\mathrm{O}$ direito à saúde no Brasil foi reconhecido tendo como princípios constitucionais basilares a universalidade e a integralidade. Estes princípios geram desafios na efetivação da saúde como direito, em especial após a vigência da Lei 12.401/2011 que redefiniu a abrangência da integralidade, reorientando de que forma serviços e produtos serão incorporados e oferecidos universalmente no sistema público de saúde. Este artigo analisa, a partir da atual configuração jurídica, como a Comissão Nacional de Incorporação Tecnológica promove a incorporação de novas tecnologias ao Sistema Único de Saúde e a política de medicamentos para os pacientes portadores de doenças raras. Foram realizados estudos de caráter exploratório, por meio de levantamentos bibliográficos, documental legal e institucional, em sites e acervos acadêmicos, inclusive internacionais, sobre os temas: doenças raras, medicamentos órfãos, integralidade e universalidade no SUS. Os resultados mostram que, no Brasil, os princípios da universalidade e da integralidade apresentam dificuldades de efetivação, quando confrontados com os processos formais de incorporação de novas tecnologias ao sistema público de saúde. Embora a Lei no 12.401 tenha trazido avanços para a melhoria da eficácia e racionalidade do SUS, sempre haverá exceção a exigir dos poderes Executivo, Legislativo e Judiciário medidas para garantir a universalidade do direito à saúde. A judicialização da saúde, nesse sentido, é e sempre será uma importante via de acesso a serviços e produtos que não estão incorporados ao sistema público de saúde para quem apresente necessidades diferenciadas.

\section{Palavras-chave}

Assistência Integral à Saúde; Doenças Raras; Legislação Sanitária; Serviços Públicos de Saúde; Sistema Único de Saúde.

\section{ABSTRACT}

The right to health in Brazil was recognized based on the fundamental constitutional principles of universality and integrality. These principles bring challenges to the effectiveness of health as a right, especially after the enactment of the Brazilian Law 12.401/2011 which has redefined the scope of the integrality, reorienting how services and products should be incorporated into the Brazilian public health system and universally offered. This paper analyses, from the current legal form, how the Committee for Technological Development acts to incorporate new technologies into the Brazilian National Health System and the policy for drugs to patients who suffers of orphans diseases. Exploratory studies were conducted in literature, juridical and institutional documents published in sites and academics productions, including the international one, using descriptors: rare diseases, orphan drugs, integrality and universality in the public health system. The results show that in Brazil the principles of universality and integrality present difficulties to be effectiveness, when facing the formal process of the incorporation of new technologies into the public health system. Although Law 12.401/11 has brought advances to improve the efficiency and rationality of the Brazilian public health system, there will always be exceptions which will demand measures of the Executive, Legislative and Judicial Powers to ensure the universal right to health. In this sense, the judicialization of health is (and always will be) an important route for those patients with rare diseases to access services and products that are not incorporated into the public health system.

\section{Keywords}

Brazilian National Public Health System; Integral Health Assistance; Law Legislation; Public Health Services; Rare Diseases. 
Aith F., Bujdoso Y., Nascimento P. R., Dallari S. G.

\section{Introdução}

A Constituição da República Federativa do Brasil de $1988^{1}$ reconhece a saúde como direito fundamental de todos e dever do Estado, a ser garantida mediante políticas econômicas e sociais que visem à redução dos riscos de agravos e doenças e ao acesso universal e igualitário às ações e serviços públicos de saúde. Reconhecida como um direito, a saúde passou a ser objeto de atenção especial da sociedade e do Estado, o que gerou ampla inovação legislativa, significativa reorganização da administração pública e proliferação de garantias jurídicas constitucionais para a sua proteção. A saúde passa a ser um bem jurídico tutelado pelo Estado e pela sociedade, merecedora de garantias jurídicas eficazes para sua fruição. Nas palavras do constitucionalista português Jorge Miranda, os direitos declaram-se, as garantias estabelecem- $\mathrm{se}^{2}$. O estabelecimento de garantias a um direito fundamental reconhecido e declarado pela Constituição se dá por meio de leis e de políticas públicas eficazes.

Dentre as garantias constitucionais que asseguram o direito à saúde no Brasil, vale destacar a criação de um sistema público de saúde universal, integral, igualitário e gratuito. Denominado Sistema Único de Saúde (SUS), o sistema público de saúde brasileiro foi modelado para o atendimento de todo ser humano em território nacional, de forma não discriminatória e equitativa. Criado pela Constituição Federal de 1988, na forma de uma rede regionalizada e hierarquizada de ações e serviços públicos de saúde, o SUS é constituído por serviços da União, dos estados, do Distrito Federal e dos municípios.

Por meio dessa rede interfederativa de serviços públicos de saúde, o Estado brasileiro oferece à população brasileira o acesso às ações e serviços voltados à efetivação do direito à saúde. A rede de serviços públicos que integra o SUS é guiada pelas diretrizes constitucionais da descentralização (política e administrativa), da integralidade de atendimento e da participação da comunidade na sua gestão ${ }^{3}$.

A descentralização política e administrativa dos serviços conduz o processo de regionalização do sistema de saúde brasileiro, integra e harmoniza os serviços dos entes federativos brasileiros (União, estados, Distrito Federal e municípios). A atual distribuição de atribuições entre esses entes federativos, pactuada por meio de várias normas jurídicas legais e infralegais, atribui aos municípios a tarefa primordial de cuidar da atenção

\footnotetext{
${ }^{1}$ BRASIL. Constituição da República Federativa do Brasil de 1988. Disponível em: <http://www.senado.gov. br/legislacao/const/con1988/ CON1988_13.07.2010/index. shtm>. Acesso em: 02 jul. 2012.

${ }^{2}$ MIRANDA, Jorge. Manual de direito constitucional. 2. ed. Coimbra: Coimbra Ed., 1998. t. 4, p. 88-89. 0 jurista oferece alguns ótimos exemplos da contraposição entre direitos e garantias: "Ao direito à vida correspondem às garantias que consistem na proibição de pena de morte e na proibição de extradição por crimes puníveis com a pena de morte segundo o direito do Estado requisitante; ao direito à liberdade e segurança a não retroatividade de lei incriminadora, o habeas corpus ou as garantias do argüido; à liberdade de expressão e de informação, a proibição de censura e a sujeição das infrações aos princípios gerais de direito criminal; à liberdade sindical, a não sujeição da eleição dos dirigentes sindicais a qualquer autorização ou homologação."

${ }^{3}$ Artigo 198 da Constituição Federal da República do Brasil de 1988.
} 
primária à saúde (atenção básica); as atenções secundária e terciária (serviços de média e alta complexidade) são divididas entre os municípios mais desenvolvidos do país, os estados e, excepcionalmente, a União. O governo federal é responsável primordialmente pela organização e coordenação do sistema, por meio da regulação dos serviços púbicos de saúde e do financiamento compartilhado com os demais entes.

A integralidade dos serviços públicos de saúde, com prioridade para as ações preventivas, abarca a noção de que o sistema público deve oferecer atenção integral às pessoas, compreendendo ações de promoção, prevenção e recuperação da saúde e englobando serviços de atenção primária, secundária e terciária. A integralidade inclui, ainda, os serviços de assistência farmacêutica e os de recuperação e reabilitação.

Reconhecida como uma diretriz do SUS, a participação da comunidade impõe a criação e manutenção de diferentes instituições de participação democrática em saúde no Brasil, sendo as mais preponderantes as fixadas pela Lei 8.142/1990": conferências e conselhos de saúde. A conferência de saúde reúne-se a cada quatro anos com a representação dos vários segmentos sociais, para avaliar a situação de saúde e propor as diretrizes para a formulação de políticas públicas nos níveis correspondentes. Nesse sentido, essas diretrizes são consideradas importantes fundamentos para a elaboração das políticas públicas de saúde e, consequentemente, para a produção das normas jurídicas de direito sanitário e para a efetivação do direito à saúde. Já os conselhos de saúde funcionam em caráter permanente e deliberativo. São órgãos colegiados compostos por representantes do governo, prestadores de serviço, profissionais da saúde e usuários e atuam na formulação de estratégias e no controle da execução da política de saúde na instância correspondente, inclusive nos aspectos econômicos e financeiros.

Para responder a tamanha responsabilidade, o Estado brasileiro conta com um financiamento constitucionalmente vinculado, regulamentado pela Lei Complementar 141/20125 - garantia orçamentária fundamental para a consolidação do sistema público de saúde no Brasil, embora a demanda por serviços ainda seja muito superior à capacidade de oferta do Estado.

Essa realidade, em que o direito reconhecido esbarra com a incapacidade estatal de suprir a demanda, provocou uma explosão de ações judiciais em busca de

\footnotetext{
${ }^{4}$ BRASIL. Presidência da República. Lei ñ 8.142, de 28 de dezembro de 1990. Dispõe sobre a participação da comunidade na gestão do Sistema Único de Saúde (SUS) e sobre as transferências intergovernamentais de recursos financeiros na área da saúde e dá outras providências. Disponível em: <http://www.planalto. gov.br/ccivil_03/leis/I8142.htm>. Acesso em: 02 ago. 2012.

${ }^{5}$ BRASIL. Presidência da República. Lei Complementar $n^{\circ} 141$, de 13 de janeiro de 2012. Regulamenta o $\S 3^{\circ}$ do art. 198 da Constituição Federal para dispor sobre os valores mínimos a serem aplicados anualmente pela União, Estados, Distrito Federal e Municípios em ações e serviços públicos de saúde; estabelece os critérios de rateio dos recursos de transferências para a saúde e as normas de fiscalização, avaliação e controle das despesas com saúde nas 3 (três) esferas de governo; revoga dispositivos das Leis nos 8.080, de 19 de setembro de 1990, e 8.689, de 27 de julho de 1993; e dá outras providências. Disponível em: <http:// www.planalto.gov.br/ccivil_03/leis/LCP/Lcp141.htm>. Acesso em: 18 out. 2012.
} 
serviços de saúde e medicamentos. Segundo dados do Conselho Nacional de Justiça, atualmente existem em torno de 240 mil ações judiciais requerendo saúde no Brasil ${ }^{6}$.

Como consequência dessa reação da sociedade ao reconhecimento da saúde como direito, o Poder Executivo Federal obteve no Congresso Nacional a aprovação da Lei $12.401 / 2012^{7}$, a qual tem significativas implicações para a diretriz da integralidade da saúde, o que afeta também o princípio da universalidade.

Assim, ao mesmo tempo em que o Brasil reconhece constitucionalmente o direito universal e igualitário à saúde, o Estado brasileiro não reúne, ainda, condições operacionais e financeiras para atender à demanda concreta por ações e serviços de saúde existentes. Nesse contexto, a efetivação do direito à saúde em respeito aos princípios constitucionais da universalidade e da integralidade está intimamente relacionada com a compreensão que se tem sobre a abrangência de tais princípios no Brasil. E tal abrangência será definida conforme a interpretação que se dê a esses princípios constitucionais, interpretação esta que será sempre moldada pela legislação e pelas políticas públicas de saúde vigentes.

\section{A integralidade no SUS à luz das inovações trazidas pela Lei 12.401/2011: protocolos clínicos, diretrizes terapêuticas e relações de serviços e medicamentos}

A integralidade aparece expressamente no artigo 198, inciso II, da Constituição Federal como uma diretriz do SUS. Ao mesmo tempo, a integralidade pode ser interpretada como um princípio constitucional do sistema à medida que o artigo $196 \mathrm{da}$ Constituição dispõe que o Estado deve adotar políticas sociais e econômicas que visem à promoção, proteção e recuperação da saúde. O artigo $7^{\circ}$ da Lei 8.080/1990 menciona expressamente a integralidade como um princípio, após reafirmar as diretrizes do Art. 198 da Constituição. Assim, a natureza jurídica da integralidade é híbrida, sendo ao mesmo tempo um princípio e uma diretriz do SUS. Para este artigo, a integralidade será considerada como um princípio ordenador do SUS. Seja como for (princípio e/ ou diretriz), é evidente que os contornos jurídicos do que se entende por integralidade ainda são bastante imprecisos, cercados de controvérsias hermenêuticas e práticas que afetam o sistema de saúde e o sistema jurídico, e que carecem de melhor compreensão.

\footnotetext{
${ }^{6}$ BRASIL. Conselho Nacional de Justiça. Notícias. Fórum debate a judicialização na área da saúde. Brasília: CNJ; 2012. Disponivel em: <http://www.cnj1.myclipp.inf.br/default.asp?smenu=ultimas \&dtlh=75087\&iABA= Not\%EDcias\&exp=>. Acesso em: 18 out. 2012.

${ }^{7}$ BRASIL. Presidência da República. Lei n 12.401, de 28 de abril de 2011. Altera a Lei n 8.080, de 19 de setembro de 1990, para dispor sobre a assistência terapêutica e a incorporação de tecnologia em saúde no âmbito do Sistema Único de Saúde - SUS. Disponível em: <http://www. planalto.gov.br/ccivil_ 03/_Ato2011-2014/2011/Lei/L12401.htm>. Acesso em: 02 ago. 2012.

8BRASIL. Presidência da República. Lei n 8.080 , de 19 de setembro de 1990. Dispõe sobre as condições para a promoção, proteção e recuperação da saúde, a organização e o funcionamento dos serviços correspondentes e dá outras providências. Disponível em: <http://www.planalto.gov.br/ccivil_03/leis//8080. htm>. Acesso em: 02 ago. 2012.
} 
A indefinição sobre os reais contornos do dever do Estado no que se refere ao oferecimento integral de serviços e produtos de saúde contribui para o incremento da judicialização da saúde no Brasil, fenômeno por meio do qual o cidadão vai ao Poder Judiciário para garantir direitos constitucionalmente garantidos de acesso universal e integral ao direito à saúde. A definição sobre quais serviços e produtos que serão incorporados ao sistema público de saúde e oferecidos de forma universal constitui, assim, um momento estratégico na conformação das garantias concretas de efetivação da saúde como direito a ser preservado de forma integral.

A primeira iniciativa mais efetiva adotada pelo Ministério da Saúde para institucionalizar o processo de incorporação tecnológica no SUS, tendo a integralidade como referência, foi a criação, sob a coordenação da Secretaria de Atenção à Saúde do Ministério da Saúde (SAS/MS), da Comissão de Incorporação de Tecnologias (CITEC), em 2006. Esta Comissão nasceu com a atribuição de "analisar a incorporação ou retirada de tecnologias de saúde, revisão de diretrizes clínicas, protocolos terapêuticos e assistenciais" ". Em 2008 a gestão da CITEC passou à responsabilidade da Secretaria de Ciência, Tecnologia e Insumos Estratégicos (SCTIE/MS).

A CITEC tinha por objetivo desenvolver os protocolos clínicos e diretrizes terapêuticas (PCDT) do Ministério da Saúde, para definir o que seria incorporado ao SUS. Os PCDTs estabelecem os critérios de diagnóstico de cada doença, o algoritmo de tratamento das doenças com as respectivas doses adequadas e os mecanismos para o monitoramento clínico em relação à efetividade do tratamento e a supervisão de possíveis efeitos adversos. Observando ética e tecnicamente a prescrição médica, os PCDTs também objetivavam criar mecanismos para a garantia da prescrição segura e eficaz ${ }^{10}$.

Embora a iniciativa tenha sido importante do ponto de vista de avanço institucional, a produção da CITEC foi bastante tímida. A Comissão aprovou somente um protocolo em 2006, um em 2007 e nenhum em 2008, produzindo pouco efeito significativo sobre as demandas judiciais. A produção da CITEC foi acelerada a partir de 2008, tendo aprovado seis protocolos em 2009, 46 em 2010 e sete em 2011, totalizando 185 durante todo o período de funcionamento ${ }^{11}$.

\footnotetext{
${ }^{9}$ BRASIL. Ministério da Saúde. Portaria n 152/GM, de 19 de janeiro de 2006. Institui o fluxo para incorporação de tecnologias no âmbito do Sistema Único de Saúde. Disponível em: <http://dtr2001.saude.gov.br/ sas/PORTARIAS/Port2006/GM/GM-152.htm>. Acesso em: 02 jul. 2012.

${ }^{10}$ BRASIL. Ministério da Saúde. Portaria $n^{\circ} 2.587$, de 30 de outubro de 2008. Dispõe sobre a Comissão de Incorporação de Tecnologias do Ministério da Saúde e vincula sua gestão à Secretaria de Ciência, Tecnologia e Insumos Estratégicos. Disponível em: <http://bvsms.saude.gov.br/bvs/saudelegis/gm/2008/ prt2587_30_10_2008.html>. Acesso em: 10 fev. 2013.

${ }^{11}$ BRASIL. Ministério da Saúde. Secretaria de Ciência, Tecnologia e Insumos Estratégicos. Comissão Nacional de Incorporação de Tecnologias no Sistema Único de Saúde. Protocolos Clínicos, Propostas submetidas e Deliberações da antiga CITEC. Brasília, DF: CONITEC; 2012b. Disponível em: <http://portal. saude.gov.br/ portal/saude/Gestor/visualizar_texto.cfm?idtxt=32707\&janela=1>. Acesso em: 01 out. 2012.
} 
A importância da relação entre integralidade e incorporação tecnológica no SUS ganhou em 2009 um novo status com a criação da Política Nacional de Gestão de Tecnologias em Saúde, por meio da Portaria 2.690/2009 ${ }^{12}$, que define a gestão de tecnologias em saúde como "o conjunto de atividades gestoras relacionadas com os processos de avaliação, incorporação, difusão, gerenciamento da utilização e retirada de tecnologias do sistema de saúde".

O Poder Judiciário levou, em 2009, o tema da incorporação tecnológica de serviços e produtos no SUS para debate público mediante uma audiência pública sobre saúde, promovida pelo Supremo Tribunal Federal com participação da sociedade civil, profissionais de saúde, gestores do governo e comunidade científica. Nesse evento, o principal argumento dos representantes da sociedade civil e do judiciário era o de que as dificuldades encontradas pelo Poder Executivo para o fornecimento de medicamentos de alto custo eram essencialmente relacionadas com má gestão de recursos. De outro lado, os profissionais da saúde e a comunidade científica estavam mais preocupados com os aspectos técnicos relacionados aos serviços e produtos oferecidos pelo sistema público de saúde e com as possíveis pressões da indústria farmacêutica para a incorporação de novas tecnologias nem sempre mais eficazes - no SUS. Já os gestores estavam mais interessados em destacar a sobrecarga financeira que a chamada judicialização da saúde impunha ao Sistema, comprometendo a execução das políticas públicas e a equidade ${ }^{13}$.

Em 2011 as discussões sobre a amplitude da integralidade no SUS motivou a aprovação da Lei 12.401/2011, que cria a Comissão Nacional de Incorporação de Tecnologias no Sistema Único de Saúde (CONITEC) e busca assegurar a transparência e a possibilidade de participação da sociedade civil nesses processos, bem como define prazos para análise e decisão dos processos de incorporação de novas tecnologias ao SUS.

A idealização da CONITEC baseou-se no modelo britânico do National Institute for Health and Clinical Excelence (NICE), instituído em 1999, com o objetivo de avaliar tecnologias de saúde a serem incorporadas pelo National Health System (NHS), por meio de protocolos assistenciais, levando em consideração a opinião dos pacientes e dos profissionais de saúde. Apesar de se basear em métodos convencionais de avaliação como custo-efetividade e eficiência,

\footnotetext{
${ }^{12}$ BRASIL. Ministério da Saúde. Portaria $n^{\circ} 2.690$, de 05 de novembro de 2009. Institui, no âmbito do Sistema Único de Saúde (SUS), a Política Nacional de Gestão de Tecnologias em Saúde. Disponivel em: <http://bvsms.saude.gov.br/bvs/saudelegis/gm/ 2009/prt2690_05_11_2009.html>. Acesso em: 08 jun. 2012.

${ }^{13}$ SUPREMO TRIBUNAL FEDERAL. Audiência Pública sobre Saúde. Brasília: Supremo Tribunal Federal; 2009. Disponível em: <http://www.stf.jus.br/portal/cms/vertexto.asp?servico=processoaudienciapublicasau de>. Acesso em: 18 set. 2012.
} 
ocasionalmente o NICE julga o valor social e científico de determinadas terapias $^{14}$, o que não ocorre na CONITEC ${ }^{15}$.

A CONITEC foi criada como um órgão colegiado de caráter permanente, integrante da estrutura regimental do Ministério da Saúde, com o objetivo de assessorar o Ministério nas atribuições relativas à incorporação, exclusão ou alteração pelo SUS de tecnologias em saúde, bem como na constituição ou alteração de PCDTs. Tem como diretrizes de atuação: a universalidade e a integralidade das ações de saúde no âmbito do SUS com base no melhor conhecimento técnico-científico disponível; a proteção do cidadão nas ações de assistência, prevenção e promoção à saúde por meio de processo seguro de incorporação de tecnologias pelo SUS; a incorporação de tecnologias por critérios racionais e parâmetros de eficácia, eficiência e efetividade adequados às necessidades de saúde; e a incorporação de tecnologias que sejam relevantes para o cidadão e para o sistema de saúde, baseadas na relação custo-efetividade ${ }^{16}$. Dentre as suas competências, destacam-se a de emitir relatório sobre a incorporação, exclusão ou alteração pelo SUS de tecnologias em saúde e sobre a constituição ou alteração de protocolos clínicos e diretrizes terapêuticas; e propor a atualização da Relação Nacional de Medicamentos Essenciais (RENAME) ${ }^{17}$.

Passados dois meses da sua criação, a Presidência da República, mediante o Decreto $7.508 / 2012^{18}$, regulamentou aspectos da Lei $8.080 / 1990$, dispondo sobre pontos relacionados à organização do SUS e prevendo a criação de uma Rede Nacional de Serviços de Saúde (RENASES) -, que "compreende todas as ações e serviços que o SUS oferece ao usuário para atendimento da integralidade da assistência à saúde"19.

A partir daí o Ministério da Saúde inicia uma importante redefinição dos marcos regulatórios, os quais definem os contornos da integralidade do SUS,

\footnotetext{
${ }^{14}$ OLIVEIRA, Cláudio Roberto; MELAMED, Clarice; MACHADO, Rejane. Políticas da 'expertise': doenças raras e gestão das tecnologias em saúde pelo SUS. Revista Brasileira de Ciência e Tecnologia e Sociedade, São Carlos, SP, v. 2, n. 2, p. 150-186, 2011.

${ }^{15}$ POLANCZYK, Carisi Anne; VANNI, Tazio; KUCHENBECKER, Ricardo de Souza. Avaliação de tecnologias em saúde no Brasil e no contexto internacional. In: NITA, Marcelo et al. Avaliação de tecnologias em saúde: evidencia clínica, análise econômica e análise de decisão. Porto Alegre: Artmed, 2010. p. 433-449.

${ }^{16}$ BRASIL. Decreto ${ }^{\circ} 7.646$, de 21 de dezembro de 2011. Dispõe sobre a Comissão Nacional de Incorporação de Tecnologias no Sistema Único de Saúde e sobre o processo administrativo para incorporação, exclusão e alteração de tecnologias em saúde pelo Sistema Único de Saúde - SUS, e dá outras providências. Disponível em: <http:// portal.saude.gov.br/portal/arquivos/pdf/DECRETO_7646_CONITEC.pdf>. Acesso em: 08 set. 2012.

${ }^{17}$ BRASIL. Ministério da Saúde. Nova Comissão Nacional de Incorporação de Tecnologias de Saúde e impacto ao Sistema Único de Saúde. Revista de Saúde Pública, São Paulo, v. 45, n. 5, p.993-996, 2011 a.

${ }^{18}$ BRASIL. Presidência da República. Decreto $n^{\circ} 7.508$, de 28 de junho de 2011. Regulamenta a Lei $n^{\circ}$ 8.080, de 19 de setembro de 1990, para dispor sobre a organização do Sistema Único de Saúde - SUS, o planejamento da saúde, a assistência à saúde e a articulação interfederativa, e dá outras providências. Disponível em: <http://www.planalto.gov.br/ ccivil_03/_ato2011-2014/2011/decreto/ D7508.htm> Acesso em: 10 out. 2012.

${ }^{19}$ Artigo 21 do Decreto $n^{\circ} 7.508 / 2011$.
} 
primeiramente com a publicação da Portaria MS 533/2012 $2^{20}$, que estabelece o elenco de medicamentos e insumos da RENAME, revogando a relação anterior ${ }^{21}$, e determinando no seu artigo $3^{\circ}$ que "a incorporação, exclusão e alteração de medicamentos e insumos na RENAME serão realizadas pelo Ministério da Saúde, assessorado pela Comissão Nacional de Incorporação de Tecnologias no SUS”. Em 2 de maio de 2012 o Ministério da Saúde institui a RENASES, mediante Portaria Ministerial $841 / 2012^{22}$, estabelecendo a relação de serviços. No mesmo sentido, foi publicada a Portaria 2009/2012 23 , que aprova o regimento interno da CONITEC.

\section{Doenças raras e medicamentos órfãos}

Como visto, os princípios da universalidade e da integralidade do SUS têm os seus contornos definidos pela legislação relacionada à matéria, mas ainda deixa muitas lacunas a serem preenchidas. Uma boa maneira de compreender os desafios relacionados à universalidade e integralidade do SUS é analisando como o sistema cuida dos portadores de doenças raras no país. Isso porque a baixa prevalência dessas doenças, associada ao alto custo dos tratamentos (quando existem), faz com que tanto a noção de integralidade de atendimento quanto a de universalidade sejam colocadas em xeque. Assim, compreender de que forma o SUS organiza o atendimento das necessidades de produtos farmacêuticos para doenças raras permite melhor compreensão dos desafios do sistema público de saúde brasileiro, em especial os desafios relacionados à universalidade da cobertura e integralidade da atenção.

Considera-se doença rara o evento patológico caracterizado pela sua relativa baixa ocorrência, ou mesmo raridade da sua ocorrência, na população em geral. Cada país define limiares próprios para essa raridade. Os Estados Unidos da América definem o critério de 75 ocorrências a cada 100 mil habitantes ${ }^{24}$, enquanto a União

\footnotetext{
${ }^{20}$ BRASIL. Ministério da Saúde. Portaria n 533, de 28 de março de 2012. Estabelece o elenco de medicamentos e insumos da Relação Nacional de Medicamentos Essenciais (RENAME) no âmbito do Sistema Único de Saúde (SUS). Disponível em: <http://bvsms.saude.gov.br/bvs/saudelegis/gm/2012/ prt0533_28_03_2012.html>. Acesso em: 10 out. 2012.

${ }^{21}$ BRASIL. Ministério da Saúde. Portaria n 1044, de 05 de maio de 2010. Aprova a $7^{a}$ edição da Relação Nacional de Medicamentos Essenciais - Rename. Disponível em: <http://www.in.gov.br/visualiza/index.js p?jornal=1\&pagina $=58 \&$ data=06/05/2010 $>$. Acesso em 10 out. 2012.

${ }^{22}$ BRASIL. Ministério da Saúde. Portaria n 841, de 02 de maio de 2012. Publica a Relação Nacional de Ações e Serviços De Saúde (RENASES) no âmbito do Sistema Único de Saúde (SUS) e dá outras providências. Disponível em: <http://bvsms. saude.gov.br/bvs/saudelegis/ gm/2012/prt0841_02_05_2012. html>. Acesso em: 10 out. 2012.

${ }^{23}$ BRASIL. Ministério da Saúde. Portaria $n^{\circ} 2.009$, de 13 de setembro de 2012. Aprova o Regimento Interno da Comissão Nacional de Incorporação de Tecnologias no Sistema Único de Saúde (CONITEC). Disponível em: <http://bvsms.saude.gov.br/ bvs/saudelegis/gm/2012/prt2009_13_09_2012.html>. Acesso em: 10 out. 2012.

${ }^{24}$ UNITED STATES FOOD AND DRUG ADMINISTRATION - FDA. The Orphan Drug Act (as amended) Code of Federal Regulations, Title 21, Revised as of April 1, 2004. Silver Spring, MD, USA: FDA, 2012. Disponível em: <http://www.fda.gov/Regulatorylnformation/Legislation/FederalFoodDrugandCosmeticActFDCAct/SignificantAmendmentstotheFDCAct/OrphanDrugAct/default.htm>. Acesso em: 01 jun. 2012.
} 
Europeia $^{25}$ adota o critério de um por 10 mil habitantes. O Brasil ainda não possui uma política específica para doenças raras e não há dado oficial nem documento que estabeleça critérios. Até o final do ano de 2012, o Portal da Saúde do Ministério da Saúde informava que uma doença rara era aquela que acometia menos de uma pessoa por dois mil habitantes ${ }^{26}$, critério semelhante ao europeu. No entanto, esse dado não está mais disponível no Portal, havendo a informação de que foi criado um grupo de trabalho para a formulação de uma Política de Atenção às Pessoas com Doenças Raras ${ }^{27}$.

Organizações internacionais, como o National Organization for Rare Disorders, estimam a existência de 6.800 diferentes doenças raras, que hoje acometeriam 30 milhões de norte-americanos ${ }^{28}$; o European Organization for Rare Diseases calcula que 30 milhões de europeus padecem de 6.000 a 8.000 doenças raras ${ }^{29}$. Outra importante fonte para se compreender o que é uma doença rara é o Orphanet30, consórcio de pesquisa que engloba cerca de 40 países, coordenado por uma equipe francesa, e que apresenta uma lista de 5.954 doenças raras. No entanto, menos de mil doenças raras se beneficiam de um mínimo de conhecimento científico ${ }^{31,32}$; parte delas dispõe de métodos diagnósticos, sem contar com tratamento reconhecido, enquanto outras possuem várias opções de tratamento.

Para o presente artigo, vale ressaltar que as discussões sobre doenças raras são importantes para o sistema de saúde à medida que estão relacionadas com a possibilidade ou não de tratamento de seus portadores pelo Estado, por meio de terapias e medicamentos. Nesse sentido, contemporaneamente essas doenças apresentam-se à sociedade em estreita relação com os chamados medicamentos órfãos, uma vez que, por sua raridade, elas não têm maiores potenciais de lucro

${ }^{25}$ EUROPEAN UNION COMMITTEE OF EXPERTS ON RARE DISEASES - EUCERD. 2012 EUCERD Report on the State of the Art of Rare Disease Activities in Europe - Part IV: European Medicines Agency Activities \& Other European Activities in the Field of Rare Diseases. Paris, France: European Union; 2012. Disponivel em: <http://www.eucerd.eu/upload/file/Reports/2012ReportStateofArt RDActivitiesIV.pdf>. Acesso em: 12 fev. 2013.

${ }^{26}$ BRASIL. Ministério da Saúde. Portal da Saúde. Doenças raras. Brasilia, DF: Ministério da Saúde; 2012. Disponível em: <http://www.brasil.gov.br/ sobre/saude/atendimento/doencas-raras>. Acesso em: 01 out. 2012.

${ }^{27}$ BRASIL. Ministério da Saúde. Portal da Saúde. Notícias. Doenças raras: Saúde ampliará ações de atenção aos pacientes. Brasília: MS; 2013. Disponível em: <http://portalsaude.saude.gov.br/portalsaude/ noticia/5495/162/ministerio-ampliara-acoes-de-atencao-aos-pacientes.html>. Acesso em: 10 fev. 2013.

${ }^{28}$ NATIONAL ORGANIZATION FOR RARE DISORDERS - NORD. Rare Disease Information. Washington, DC, USA: NORD; 2012. Disponível em: <http://www.rarediseases.org/rare-disease-information>. Acesso em: 08 jul. 2012.

${ }^{29}$ EUROPEAN ORGANISATION FOR RARE DISEASES - EURODIS. About Rare Diseases. London: EURODIS; 2012. Disponível em: <http://www.eurordis.org/pt-pt/doencas-raras>. Acesso em: 09 jul. 2012.

${ }^{30}$ ORPHANET. Rare Diseases and Orphan Drugs. Paris, France: Orphanet, 2012. Disponível em: <http://www. orpha.net/consor/cgi-bin/>. Acesso em: 13 jul. 2012.

${ }^{31}$ Id. Ibid.

${ }^{32}$ EUROPEAN MEDICINES AGENCY. Special Topics - Medicines for rare diseases. London: EMEA; 2012. Disponivel em: <http://www.ema.europa.eu/ema/index.jsp?curl=pages/special_topics /general/general_>. Acesso em: 01 jul. 2012. 
para a indústria farmacêutica, que não demonstra interesse em investir na pesquisa e desenvolvimento de drogas para o tratamento dessas doenças.

O termo medicamento órfão foi utilizado pela primeira vez no ano de 1968, pelo pediatra Harry Shirkey, em um editorial da revista Pediatrics para se referir a uma droga de adulto para uso pediátrico ${ }^{33}$. Trata-se de um medicamento potencialmente útil, não disponível no mercado, em função de sua exploração não ser considerada lucrativa devido à baixa escala da demanda.

Doenças raras e medicamentos órfãos, associados ou não uns aos outros, trazem uma complexidade própria à universalização da atenção em saúde que os torna bastante interessantes, como objeto de estudos dos campos do direito e da gestão pública, para experimentar os limites das prerrogativas estatais em prover saúde à população.

Para compreender a exata extensão dos princípios da universalidade e da integralidade no sistema de saúde brasileiro, o presente artigo propõe-se a abordar esses princípios a partir de dois cenários atualmente verificados no país: a) a nova conformação do princípio da integralidade dada pela Lei 12.401/2011, que organiza de que forma o Estado brasileiro irá definir as ações e serviços de saúde a serem oferecidos pelo SUS; e b) a legislação e política pública de saúde voltadas ao tratamento das doenças raras. Sob esse enfoque, objetivamos neste artigo detalhar os principais desafios para o oferecimento, pelo sistema público de saúde, de um atendimento universal e integral para todas as pessoas que tiverem necessidades legítimas e fundamentais de acesso a serviços de saúde.

\section{Método}

Este artigo insere-se no âmbito da pesquisa "Direito à Saúde e Democracia Sanitária: Pontes para a Cidadania”, desenvolvida pelo Núcleo de Pesquisa em Direito Sanitário da Universidade de São Paulo e apresenta os resultados de um estudo de caráter exploratório, realizado mediante levantamento legislativo, bibliográfico, documental e institucional, com enfoque nos temas operacionais da investigação, notadamente os temas de doenças raras, medicamentos órfãos, integralidade, universalidade e incorporação de novas tecnologias ao SUS.

A identificação de instituições públicas que lidam com os temas das doenças raras e medicamentos órfãos orientou a busca legislativa e documental. Os resultados encontrados foram confrontados com os aportes descritos e analisados pela bibliografia selecionada.

\footnotetext{
${ }^{33}$ LABSON, Michael S. Pediatric Priorities: Legislative and Regulatory Initiatives to Expand Research in Use of Medicine in Pediatric Patients. Journal of Health Care and Law Policy, Baltimore, MD, USA, v. 6, n. 34, p. 33-72, 2000.
} 
A pesquisa exploratória relacionando integralidade, universalidade, incorporação tecnológica e doenças raras mostrou-se extremamente proveitosa para a compreensão dos aspectos envolvidos na discussão sobre os conceitos de universalidade e integralidade dentro do sistema de saúde público brasileiro, em especial se considerarmos que esses conceitos ainda possuem contornos indefinidos e bastante controversos.

Detalhadamente, no que se refere à abordagem qualitativa empreendida após a coleta dos dados legislativos e documentais, as seguintes etapas foram cumpridas: a) identificação e interpretação dos textos normativos que organizam e estruturam o princípio da universalidade e a diretriz de integralidade do SUS; b) identificação e interpretação da legislação brasileira que organiza o tratamento de doenças raras, aí incluído o oferecimento de assistência farmacêutica de medicamentos órfãos no Brasil; c) levantamento e interpretação de documentos produzidos pelo Conselho Nacional de Saúde (CNS) sobre doenças raras e medicamentos órfãos; d) levantamento e interpretação de informações constantes de bases de dados internacionais sobre doenças raras e medicamentos órfãos (Orphanet, Eurodis, NORD e EMEA); e e) identificação dos protocolos clínicos para doenças raras e medicamentos órfãos solicitados à CITEC e a sua sucedânea, a CONITEC.

A análise qualitativa dos dados, num primeiro momento, buscou identificar as diferentes dimensões analíticas ou temas relacionados aos conceitos abordados, agrupando-os pela similaridade de seu conteúdo, para em seguida identificar claramente: a) o rol de medicamentos relativos a doenças raras formalmente incluídos na Política Nacional de Assistência Farmacêutica; e b) a efetiva participação das organizações de portadores de doenças raras no recente dimensionamento das demandas feitas à CITEC e à CONITEC para a incorporação de tecnologias relacionadas com as doenças raras e os medicamentos órfãos e a efetividade dos resultados assim alcançados.

Para o levantamento das doenças raras tratadas pelo SUS, utilizou-se inicialmente o número da Classificação Internacional de Doenças: CID-10, que consta da portaria que especifica as "Situações clínicas tratadas pelo Componente Especializado da Assistência Farmacêutica (CEAF)"34. Para identificar as doenças raras tratadas no âmbito do sistema público brasileiro também foi utilizado o banco de dados do Orphanet, tendo como parâmetro de doença rara adotado pelo Brasil, a prevalência e incidência da moléstia. Para relacionar as doenças raras e medicamentos órfãos constantes do Componente Estratégico ${ }^{35}$, dos protocolos

\footnotetext{
${ }^{34}$ BRASIL. Ministério da Saúde. Situações clínicas tratadas pelo Componente Especializado da Assistência Farmacêutica. Brasília, DF: Ministério da Saúde; 2012c. Disponível em: <http://portal.saude.gov.br/portal/arquivos/pdf/situacoes_clinicas_ceaf_jan_2012.pdf>. Acesso em: 02 jul. 2012.

${ }^{35}$ BRASIL. Ministério da Saúde. Secretaria de Ciência, Tecnologia e Insumos Estratégicos. Comissão Nacional de Incorporação de Tecnologias no Sistema Único de Saúde. Protocolos Clínicos, Propostas submetidas e Deliberações da antiga CITEC. Brasília, DF: CONITEC, 2012. Disponível em: <http://portal.saude.gov.br/ portal/saude/Gestor/area.cfm?id_area=1611>. Acesso em: 01 out. 2012.
} 
da CONITEC $^{36}$ e da CITEC $^{37}$ e do Orphanet foram utilizados o nome da doença e o número da CID-10.

O levantamento de medicamentos órfãos ofertados pelo SUS através do CEAF e Componente Estratégico, assim como das demandas de incorporação da CITEC e da CONITEC, foi realizado em duas etapas, uma vez que o banco de dados do Orphanet nem sempre se mostrou sensível ao nome da substância, sendo necessário o nome fantasia europeu. Para esse levantamento utilizou-se o Guia de Remédios (substâncias ativas) do site Medicinanet ${ }^{38}$, que fornece o nome fantasia/ marca do medicamento. Com o nome fantasia verificou-se se o medicamento era considerado órfão, para qual doença estava referenciado e se coincidia com a listagem brasileira.

Os resultados da pesquisa foram consolidados e são apresentados no presente artigo, seguidos de uma discussão crítica com apoio da bibliografia referenciada e focada na compreensão dos atuais contornos dos princípios da universalidade e da integralidade do sistema público de saúde brasileiro.

\section{Resultados}

A pesquisa realizada alcançou resultados importantes que permitem melhor compreensão dos obstáculos existentes para a concretização efetiva dos princípios da integralidade e da universalidade no SUS. Os dados encontrados também permitem a identificação de possíveis caminhos que possam ser seguidos para o constante aperfeiçoamento do sistema de saúde brasileiro.

\section{Proteção de doenças raras no Brasil e medicamentos órfãos: identificação de limites práticos à efetivação dos princípios da universalidade e integralidade no que se refere a essas doenças.}

A proteção dada pelo Estado brasileiro para as denominadas doenças raras explicita limites práticos para a aplicação integral dos princípios da universalidade e da integralidade no que se refere a essas doenças.

Preliminarmente, vale ressaltar que a literatura apresenta como principais empecilhos para o desenvolvimento de produtos médicos destinados ao tratamento de doenças raras: dificuldade em encontrar pacientes para testes de desenvolvimento de estudos clínicos em função de sua raridade; dificuldade em alcançar relevância

\footnotetext{
${ }^{36}$ BRASIL. Ministério da Saúde. CONITEC, Secretaria de Ciência, Tecnologia e Insumos Estratégicos. Uso offlabel: erro ou necessidade? Revista de Saúde Pública, São Paulo, v. 46, n. 2, p. 395-397, 2012.

${ }^{37}$ BRASIL. Ministério da Saúde. Secretaria de Ciência, Tecnologia e Insumos Estratégicos. Comissão Nacional de Incorporação de Tecnologias no Sistema Único de Saúde. Protocolos Clínicos, Propostas submetidas e Deliberações da antiga CITEC, cit.

${ }^{38}$ MEDICINANET. Guia de Remédios. Disponível em: <http://www.medicinanet.com.br/categorias/medicamentos.htm>. Acesso em: 01 jul. 2012.
} 
clínica e de custo-efetividade, dificultando estudos de medicina baseada em evidências, por conta do baixo número de sujeitos, estando a maioria dos estudos em fase experimental; alto custo de desenvolvimento de medicamento comprometendo o orçamento dos sistemas públicos de saúde; e baixa perspectiva de mercado, necessitando de subsídios públicos para seu desenvolvimento ${ }^{39,40,41}$.

No que se refere à assistência farmacêutica dos portadores de doenças raras, os princípios e diretrizes gerais do acesso ao tratamento medicamentoso no país foram estabelecidos pela Política Nacional de Assistência Farmacêutica ${ }^{42}$. Posteriormente, a Portaria GM 204/200743, ao regulamentar os blocos de financiamento do SUS, definidos pelos pactos pela vida e de gestã ${ }^{44}$, definiu que o bloco de financiamento de assistência farmacêutica seria constituído por três componentes - o básico, o estratégico e o de medicamentos de dispensação excepcional. O componente básico destina-se à aquisição de medicamentos e insumos da assistência farmacêutica no âmbito da atenção básica em saúde e àqueles relacionados a agravos e programas de saúde específicos, no âmbito da atenção básica ${ }^{45}$. O componente estratégico do bloco de financiamento da assistência farmacêutica destina-se ao financiamento de programas de saúde estratégicos, tais como os programas de controle de endemias (tuberculose, hanseníase, malária, leishmaniose, doença de chagas e outras doenças endêmicas de abrangência nacional ou regional); de HIV/AIDS e os que envolvem imunobiológicos ${ }^{46}$. O componente "medicamentos de dispensação excepcional" seria definido em "portaria específica", cabendo a responsabilidade pelo financiamento para sua aquisição ao Ministério da Saúde ${ }^{47}$.

Em 2009 a Portaria GM 2.981/20098 ${ }^{48}$ aprovou o CEAF, alterando para essa denominação a antiga designação "componente de medicamentos de dispensação

\footnotetext{
${ }^{39}$ GINSBURG, Geoffrey Steven et al. Implications of pharmacogenomics for drug development and clinical practice. Archives of Internal Medicine, Bethesda, MD, USA, v. 165, n. 20, p. 2331-2336, Nov. 2005.

${ }^{40}$ REIDENBERG, Marcus M. Are drugs for rare diseases "essential”? Bulletin of the World Health Organization, v.84, n. 9, p. 686, Sept. 2006.

${ }^{41}$ STOLK, Pieter et al. "Rare essentials": drugs for rare diseases as essential medicines. Bulletin of the World Health Organization, v.84, n. 9, p. 745-751, Sept. 2006.

${ }^{42}$ BRASIL. Ministério da Saúde. Conselho Nacional de Saúde. Resolução n 338, de 06 de maio de 2004. Aprovar a Política Nacional de Assistência Farmacêutica. Disponível em: http://portal.saude.gov.br/portal/ arquivos/pdf/resol_cns338.pdf>. Acesso em: 09 set. 2012.

${ }^{43}$ BRASIL. Ministério da Saúde. Portaria n ${ }^{\circ}$ 204/GM, de 29 de janeiro de 2007. Regulamenta o financiamento e a transferência dos recursos federais para as ações e os serviços de saúde, na forma de blocos de financiamento, com o respectivo monitoramento e controle. Disponível em: <http://portal.saude.gov.br/portal/ arquivos/pdf/portaria\% 20204.pdf>. Acesso em: 02 jul. 2012.

${ }^{44}$ BRASIL. Ministério da Saúde. Portaria n 699/GM, de 30 de março de 2006. Regulamenta as Diretrizes Operacionais dos Pactos Pela Vida e de Gestão. Disponível em: <http://portal.saude.gov.br/portal/arquivos/pdf/Portaria_699_2006.pdf>. Acesso em: 02 jul. 2012.

${ }^{45}$ Artigo 25 da Portaria 204/GM.

${ }^{46}$ Artigo 26 da Portaria 204/GM.

${ }^{47}$ Artigo 27 da Portaria 204/GM.

${ }^{48}$ BRASIL. Ministério da Saúde. Portaria n².981, de 26 de novembro de 2009. Aprova o Componente Especializado da Assistência Farmacêutica. Disponível em: <http://portal.saude.gov.br/portal/arquivos/pdf/ portaria_gm_2981_3439_ceaf.pdf>. Acesso em: 02 jul. 2012.
} 
excepcional" e definindo-o como estratégia de acesso integral ao tratamento medicamentoso, em nível ambulatorial, cujas linhas de cuidado estejam definidas nos PCDTs publicados pelo Ministério da Saúde ${ }^{49}$.

Por essas considerações pode-se dizer que os estatutos legais permitem a incorporação de medicamentos para doenças raras ao rol de medicamentos dispensados pelo SUS, mas que essa preocupação não está estruturalmente definida no sistema, na forma de programa, ação ou estratégia específicos. Atualmente, os componentes estratégicos especializados cobrem o fornecimento de alguns desses medicamentos, como veremos adiante, sendo o componente especializado o principal caminho para a assistência farmacêutica dos chamados medicamentos órfãos para as doenças raras.

O Ministério da Saúde lançou, também em 2009, a Política Nacional de Atenção Integral em Genética Clínica (PNAIGC), tendo os pacientes de doenças raras como principais beneficiários ${ }^{50}$. Trata-se de uma política que busca articular as três esferas de gestão do SUS e tem como objetivos identificar os determinantes/condicionantes dos principais problemas de saúde relacionados a doenças genéticas para elaboração de ações e políticas públicas no setor; incentivar pesquisas para estudos de custo-efetividade, eficácia e qualidade e incorporação de tecnologias na área de genética clínica; e qualificar a assistência em conformidade com os princípios da integralidade e da Política Nacional de Humanização (PNH).

Até o final do ano de 2012 o Portal Brasil ${ }^{51}$ veiculava uma menção explícita a doenças raras, associada ao PNAIGC, e informava existirem, no país, 26 PCDTs relacionadas a essas doenças, responsáveis pelo fornecimento de 45 medicamentos ou tratamentos cirúrgicos e clínicos, além de outros quatro protocolos em desenvolvimento.

A complexidade do tema e de suas interfaces com os princípios da integralidade e universalidade do sistema público de saúde pode ser bem ilustrada pela síntese de uma audiência pública para discussão da PNAIGC, realizada em Porto Alegre, em junho de 2012, pelo Núcleo de Saúde, Previdência e Assistência Social da Procuradoria da República do Rio Grande do Sul:

\footnotetext{
${ }^{49}$ Artigo $8^{\circ}$ da Portaria 2.981/2009.

${ }^{50}$ BRASIL. Ministério da Saúde. Portaria $n^{\circ} 81$, de 20 de janeiro de 2009. Institui, no âmbito do Sistema Único de Saúde (SUS), a Política Nacional de Atenção Integral em Genética Clínica. Brasília, DF: Diário Oficial da União; 20 jan. 2009. Disponível em: <http://dtr2001.saude.gov.br/sas/PORTARIAS/Port2009/ GM/GM81.htm>. Acesso em: 02 jul. 2012.

${ }^{51} \mathrm{O}$ dado constante do Portal possui valor informativo uma vez que foi divulgada pelo Governo no formato de informação ao público, resumindo dados sobre a atuação governamental no campo das doenças raras. Face à relevância do dado e considerando-se que o Portal Brasil é uma fonte oficial de informações, optou-se pela manutenção do dado no artigo, por ser de alta relevância para as discussões a serem desenvolvidas. A referida informação ficou disponível no Portal até o final do ano de 2012, tendo ficado indisponibilidade a partir de janeiro de 2013. BRASIL. Ministério da Saúde. Portal da Saúde. Doenças raras, cit.
} 
(a) a necessidade de inclusão das pessoas com doenças genéticas raras nos SUS; (b) a necessidade de uma política pública que contemple uma linha de cuidado integral que vá desde o diagnóstico até o tratamento (hábitos de vida, reabilitação, tratamento específico), passando pelo aconselhamento genético; (c) a necessidade de criação de rede de assistência; (d) a necessidade de criação de instituições de reabilitação, escolarização e, para determinadas situações, morada ("nurseries", para cuidados médicos e não médicos); (e) necessidade de avaliação diferenciada para incorporação de tecnologias e reavaliação periódica; (f) necessidade de maior atenção às doenças genéticas raras nas faculdades da área da saúde e educação $0^{52}$.

Uma vez identificada a evidente incipiência do PNAIGC e a dificuldade de obtenção de informações oficiais consolidadas sobre a referida política, a pesquisa focou na compreensão sobre como o Estado brasileiro protege as doenças raras no âmbito dos programas do CEAF e do componente estratégico da assistência farmacêutica.

Os resultados obtidos são bastante reveladores. Dos 313 CIDs constantes do CEAF, 101 (32,3\%) referem-se a doenças raras ${ }^{53}$. No entanto, do total de 248 medicamentos relacionados, apenas 18 (7,2\%) destinam-se aos CIDs de doenças raras ${ }^{54}$. E mais: os 45 medicamentos órfãos mencionados como integrantes da PNAIGC não constam do CEAF. No que se refere ao componente estratégico foram encontrados nove medicamentos órfãos ${ }^{55}$ - um deles consta também do CEAF - e quatro doenças raras $^{56}$ - uma delas presente também na lista do CEAF.

Resulta que, somadas as disponibilidades dos dois componentes, chega-se a 104 doenças raras elencadas, cobertas por 26 medicamentos. Apesar de serem

\footnotetext{
${ }^{52}$ MINISTÉRIO PÚBLICO FEDERAL. Procuradoria da República do Rio Grande do Sul - Núcleo de Saúde. Audiência pública para discussão de uma Política Nacional de Atenção Integral em Genética Clínica. Porto Alegre, RS: Ministério Público Federal; 2012. Disponível em: <http://www.prrs.mpf.gov.br/home/audiencias/ genetica-clinica/ata_aud_genetica-clinica_11-06.pdf>. Acesso em: 12 jul. 2012.

${ }^{53}$ Lista das 101 doenças raras atendidas pelo CEAF, segundo o CID-10: B18.2; B22.2; D18.0; D46.1; D46.7; D56.1; D57.2; D59.0; D59.1; D60.0; D61.0; D61.1; D61.2; D69.3; D70; D80.0; D80.8; D81.1; D81.2; D81.3; D81.4; D81.5; D81.7; D81.8; D82.0; D82.1; D84.1; E20.1; E20.8; E22.0; E22.1; E22.8; E23.0; E23.2; E25.0 ; E25.2; E27.0; E27.1; E27.4; E28.2; E70.0; E75.2; E78.0; E78.1; E78.2; E78.3; E78.4; E78.6; E83.0; E83.3; E84.0; E88.0; E88.8; G12.2; G20; G24.0; G24.1; G24.4; G24.5; G24.8; G30.0; G35; G40.0; G40.1; G40.2; G40.3; G40.4; G40.5; G40.8; G61.0; G70.0; G82.1; I27.0; K50.0; K51; K75.4; K86.1; L44.0; M02.3; M05.0; M06.8; M07.3; M08.0; M32; M33.0; M33.1; M33.2; M45; M81.8; M88.0; M88.8; N04.0; N18.0; N25.8; Q80.0; Q80.1; Q80.2; Q80.3; Q80.8; Q82.8; Q96.

${ }^{54}$ Lista dos 18 medicamentos órfãos ofertados pelo CEAF: Alfapeginterferona; Alfavelaglicerase; Azatioprina; Betainterferona; Ciclofosfamida; Deferasirox; Desmopressina; Etanercepte; Filgrastim; Iloprosta; Imiglucerase; Miglustate; Natalizumabe; Octreotida; Riluzol; Selegilina; Sildenafila; Toxina Botulínica.

${ }^{55}$ Lista de medicamentos órfãos do componente estratégico: ácido tranexâmico ;complexo protrombínico parcialmente ativado; concentrado de Fator VIII para Doença de von Willebrand; concentrado plasmático de fator IX; concentrado plasmático de fator VIII; concentrado plasmático de fator XIII; concentrado plasmático de fibrinogênio (Fator I) ; fator VII ativado recombinante e a desmopressina que consta no CEAF.

${ }^{56}$ Lista de doenças raras do componente estratégico: doença de Von Willebrand; mieloma múltiplo; hemofiliae lúpus que consta no CEAF.
} 
dados superiores à expectativa inicial - existência de 26 PCDTs e 45 tratamentos, entre medicamentoso, clínico e cirúrgico -, eles indicam que a cobertura brasileira para essas doenças é extensa, o que resulta, ao menos em tese, em uma violação aos princípios da integralidade e universalidade.

Ao se confrontar a lista de 101 doenças raras que possuem referência na CID-10 e que estão presentes no componente especializado, encontraram-se 38 $(37,6 \%)$ delas com protocolos clínicos gerados pela CITEC ou CONITEC.

A fim de se dimensionar a iniciativa social para novos atendimentos de doenças raras no SUS, levantaram-se as demandas por incorporação tecnológica, encaminhadas à CITEC (2006-2011) e à CONITEC (a partir de 2012). Encontraram-se demandas em relação a seis doenças raras e a 20 medicamentos órfaos não constantes dos componentes especializados ou estratégicos.

De um total de 263 pedidos protocolados ${ }^{57}$ na CITEC, foram julgados 185 , sendo 140 referentes a medicamentos. Destes, 70 foram incorporados, 46 não incorporados, nove foram excluídos do SUS, seis foram arquivados a pedido do demandante, dois foram considerados fora do escopo da CITEC, cinco foram mantidos na lista SUS e dois excluíram tecnologias, pois o registro junto à Agência Nacional de Vigilância Sanitária (ANVISA) foi cancelado. Dos protocolos arquivados e fora do escopo do CITEC, nenhum se referia à doença rara ou a medicamento órfão, e das tecnologias mantidas somente uma se referia a uma doença rara, a miastenia grave, mas nenhuma a medicamento órfão.

Dos 70 protocolos de medicamentos incorporados, 39 (55,7\%) faziam referência a 15 diferentes doenças raras ${ }^{58}$, uma das quais não constava do CEAF ou do componente estratégico, e $26(37,1 \%)$ se referiam a 18 diferentes medicamentos órfãos, dos quais sete medicamentos não foram encontrados nas listas do CEAF nem do componente estratégico ${ }^{59,60}$.

Dos 46 medicamentos não incorporados, poucos protocolos tratavam de doenças raras e medicamentos órfãos, somente $13(28,2 \%)$ se referiam a 12 diferentes doenças raras, sendo três destas não atendidas pelo CEAF nem pelo componente

\footnotetext{
${ }^{57}$ As demandas podem pleitear inclusão, exclusão ou substituição de tecnologias de saúde no SUS.

${ }^{58}$ Lista de doenças raras com PDCT do CITEC atendidas pelo CEAF e estratégico: anemia hemolítica autoimune; angioedema; aplasia pura crônica adquirida da série vermelha; artrite reumatóide; doença de Crohn; doença de Gaucher; esclerose múltipla; hemofilia; hepatite C; hipertensão arterial pulmonar; lúpus eritematoso sistêmico; miastenia gravis; púrpura trombocitopênica idiopática (PTI); retocolite ulcerativa; talassemia maior.

${ }^{59}$ Lista de medicamentos órfãos incorporados pela CITEC: a) atendidas CEAF e estratégico: Alfapeginterferona; Alfavelaglicerase; Azatioprina; Ciclofosfamida; Deferasirox; Etanercepte; Iloprosta; Imiglucerase; Miglustate; Natalizumabe; Sildenafila; b) não atendidas CEAF e estratégico: Bevacizunabe; Dasatinibe; Deferiprona; Inibidor de C1 Esterase; Mesilato de Imatinibe; Nilotinibe e Vincristina.

${ }^{60}$ Chamou a atenção a quantidade de protocolos para uma única doença rara, a doença de Gaucher, com seis demandas.
} 
estratégico ${ }^{61}$, e sete protocolos se referiam a quatro diferentes medicamentos órfãos que não constam das listas ${ }^{62}$.

Dos nove protocolos de medicamentos excluídos, seis $(66,6 \%)$ mencionavam doenças raras e três, dois diferentes medicamentos órfãos, enquanto a ciproterona, apesar de excluída pelo CITEC, continua na lista CEAF para tratamento de puberdade precoce.

Em relação à CONITEC, até outubro de 2012, foram protocolados 106 pedidos; destes, 84 eram de medicamentos. Dos medicamentos, um protocolo foi encerrado a pedido do demandante; 23 foram recusados em função da documentação; 34 estão em análise; e 26 foram julgados: 10 como não incorporadas e 16 como incorporadas.

Dos 23 protocolos recusados em função da documentação, seis (26\%) se referiam a quatro doenças raras, sendo duas não atendidas pelas listas ${ }^{63}$ e oito referentes a cinco medicamentos órfãos, nenhum deles nas listas do CEAF e Estratégico ${ }^{64}$.

Dos 34 protocolos em análise, nove (26,5\%) se referiam a sete doenças raras, todas atendidas pelo $\mathrm{CEAF}^{65}$, e seis a medicamentos órfãos em que só um consta nas listas ${ }^{66}$.

Dos dez protocolos não incorporados pela CONITEC, três (30\%) se referiam a duas doenças raras já atendidas pelo CEAF (doença de Crohn e hipertensão arterial pulmonar) e quatro se referiam a medicamentos órfãos ${ }^{67}$,

Dos 17 protocolos incorporados, dez $(58,8 \%)$ se referiam a seis doenças raras, somente uma não atendida pelo $\mathrm{CEAF}^{68}$, e três a dois medicamentos órfãos, só um deles disponível nas listas ${ }^{69}$.

Esses dados indicam que as demandas que tratam de doenças raras são predominantes entre os protocolos de incorporação tanto da CITEC (55,7\%), como

${ }^{61}$ Lista das doenças Raras não incorporadas e não atendidas pelo CEAF e estratégico: fenômeno de Raynaud; glomerunefrite lupicae síndrome periódica associada à criopirina CAPS;

${ }^{62}$ Lista de medicamentos órfãos não incorporados pelo CITEC e não atendidos pelo CEAF e estratégico: ácido zoledronico; bortezomibe; bosentana; cloridrato de cinacalcete;.

${ }^{63}$ Lista das doenças raras com protocolos recusados por problemas de documentação no CONITEC: artrite reumatoide e síndrome de Turner atendidas pelo CEAF e hiperamonemia e síndrome de Hunter não atendidas.

${ }^{64}$ Lista de medicamentos órfãos recusados por problemas de documentação no CONITEC não disponíveis no CEAF nem estratégico: aspartato de ornitina; bevacizumabe; cloridrato de cinacalcete/ Sencipar; idursulfase; trastuzumabe.

${ }^{65}$ Lista das doenças raras em análise no CONITEC atendidas pelo CEAF: acromegalia; artrite psoriatica; espondilite anquilosante; fibrose cística; hepatite C; hipertensão arterial pulmonar; retocoliteulcerativa.

${ }^{66}$ Lista de medicamentos órfãos em análise no CONITEC: acetato de lanreotida; ambrisentana; golimumabe; pegvisomanto; ustequinumabe e Etanercepte dispensada pelo CEAF.

${ }^{67}$ Lista de medicamentos órfãos não incorporados pela CONITEC: ambrisentana e golimumabe não atendidados pelo CEAF e Etanecepte e Toxina Botulínica, atendidas pelo CEAF

${ }^{68}$ Lista das doenças raras incorporadas pelo CONITEC: artrite reumatoide, esclerose múltipla; esclerose sistêmica; retocolite ulcerativa; hepatite $\mathrm{C}$ e deficiência de biotinidase, esta não atendida pelas listas.

${ }^{69}$ Lista de medicamentos órfãos incorporados pela CONITEC: sildenafila e trastuzumabe (não dispensado pelo CEAF e estratégico). 
da CONITEC (58,8\%), deixando evidente a tensão entre esse tipo de doença e os princípios da universalidade e integralidade.

\section{Ausência de institucionalidade específica para reconhecimento e incorporação de medicamentos para doenças raras no sistema público de saúde do Brasil: os medicamentos órfãos}

A discussão sobre doenças raras impõe uma abordagem conjunta com os denominados medicamentos órfãos, uma vez que geralmente estes são essenciais para o tratamento terapêutico dos portadores de doenças raras. No Brasil não há uma política ou órgão específicos para regulação e fiscalização dessas drogas, como ocorre, por exemplo, nos Estados Unidos e na Europa.

Em geral são dois os critérios empregados para definir se um medicamento é órfão: a) o epidemiológico - prevalência ou incidência da doença em uma população; e b) o econômico - presunção de não rentabilidade do medicamento destinado ao tratamento, pela baixa demanda ${ }^{70}$.

Nos Estados Unidos foi criada em 1982 uma entidade para lidar especificamente com essa modalidade de medicamentos, o Office of Orphan Products Development (OOPD), vinculado à Food and Drug Administration. Esse órgão se baseou inicialmente em critérios econômicos para o desenvolvimento de medicamentos órfãos, quando instituiu o Orphan Drug Act (ODA), em 1983. No entanto, posteriormente, em 2004, quando revisou a legislação, adotou o critério epidemiológico. São três os fundamentos para esse critério: o medicamento deve ser mais efetivo que o medicamento disponível, mais seguro que o aprovado e, no caso de não haver medicamento órfão, este novo produto, apesar de não garantir efetividade ou segurança, deve contribuir significativamente para o tratamento do paciente ${ }^{71}$.

O OOPD analisa produtos médicos que são promissores para o tratamento de doenças raras, trabalhando em conjunto com médicos, academia, centros de pesquisa, entidades profissionais, agências governamentais, indústria e grupos de pacientes com doenças $\operatorname{raras}^{72,73}$. Desde 1983, o órgão recebeu 2.533 pedidos, dos quais, 394 estão no mercado como exclusivamente órfãos. Em 2011, houve 334 novos requerimentos ${ }^{74}$.

\footnotetext{
${ }^{70}$ HAFFNER, Marlene E. Focus on research: adopting orphan drugs - two dozen years of treating rare diseases. The New England Journal of Medicine, Massachusetts, NE, USA, v.354, n. 5, p. 445-447, 2006.

${ }^{71}$ GINSBURG, Geoffrey Steven, et al. op. cit.

${ }^{72}$ UNITED STATES FOOD AND DRUG ADMINISTRATION - FDA. Developing Products for Rare Diseases \& Conditions. FDA, 2012. Disponível: <http://www.fda.gov/ForIndustry/Developing Productsfor RareDiseasesConditions/default.htm>. Acesso em: 01 jun. 2012.

${ }^{73}$ Infelizmente não encontramos esclarecimentos sobre como ocorre essa participação, além de não ser assegurado acesso às informações pelos grupos de pacientes que contribuíram para o desenvolvimento do produto.

${ }^{74}$ OFFICE OF ORPHAN PRODUCTS DEVELOPMENT - OOPD. 2011 Report. Silver Spring, MD, USA: FDA; 2012. Disponível em: <http://www.fda.gov/downloads/AboutFDA/ReportsManualsFormsReports/BudgetReports/UCM298358.pdf>. Acesso em: 14 jul. 2012.
} 
Na Europa quem trata de medicamentos órfãos é o Committee for Orphan Medicinal Products (COMP), da European Medicines Agency (EMEA). A agência foi criada em 1999 e, desde o início, teve como base critérios epidemiológicos para suas avaliações, por considerá-los mais vantajosos do que os econômicos ${ }^{75}$, conforme o Regulamento $141 / 1999^{76}$. A EMEA parte do princípio de que a indústria farmacêutica não tem interesse em desenvolver um medicamento órfão nas condições normais de mercado, e oferece incentivos para o desenvolvimento desses produtos. O COMP avalia os pedidos de designação de um determinado medicamento como órfão. Em caso de deferimento do pedido, a droga adquire o status de órfão, havendo incentivos, como apoio para seu desenvolvimento, reduções de taxas de comercialização e autorizações e proteção no mercado quando estiver autorizado. O COMP possui três cadeiras para representantes de organizações de pacientes, que são nomeados pela Comissão Europeia ${ }^{77}$. Desde sua implementação, o comitê emitiu 1.005 pareceres positivos e recomendou 1.449 aplicações para medicamentos órfãos ${ }^{78}$, e a EMEA registrou 930 medicamentos órfãos ${ }^{79}$.

No Brasil, a ANVISA é a entidade estatal responsável pela aprovação de registros e comercialização de medicamentos, de acordo com a Lei 9.782/199980. No entanto, a agência não tem a atribuição de determinar se o medicamento registrado é ou não órfão, assim como não há em vigor qualquer tipo de conduta diferenciada a ser oferecida para essas drogas, tal como ocorre nos Estados Unidos e na Europa.

\section{Doenças raras e instâncias de participação}

Na falta de uma estruturação pública adequada para o tratamento de doenças raras, a sociedade vocaliza suas demandas nos espaços participativos do SUS e com isso pressiona o Estado a aperfeiçoar o tratamento dessas doenças em observância aos princípios da universalidade e integralidade.

Em 2011, o CNS realizou duas consultas públicas para revisar suas resoluções. Na consulta para atualização normativa da Resolução 196/1996 ${ }^{81}$ - voltada às

\footnotetext{
${ }^{75}$ EUROPEAN MEDICINES AGENCY. Special Topics - Medicines for rare diseases, cit.

${ }^{76}$ PARLAMENTO EUROPEU. Conselho Europeu. Regulamento (CE) n 141/2000 de 16 de Dezembro de 1999. Relativo aos medicamentos órfãos. JOL 18 de 22.1.2000, p. 1-5. Disponível em: <http://eur-lex.europa. eu/Notice.do?val=237362: cs\&lang=pt\&list=237362:cs,\&pos=1\&page=1\&nbl=1\&pgs=10\&hwords=\&che cktexte=checkbox\&visu=\#texte>. Acesso em: 10 jul. 2012.

${ }^{77}$ EUROPEAN MEDICINES AGENCY. Special Topics - Medicines for rare diseases, cit.

${ }^{78}$ EUROPEAN UNION COMMITTEE OF EXPERTS ON RARE DISEASES -EUCERD. 2012 EUCERD Report on the State of the Art of Rare Disease Activities in Europe - Part IV: European Medicines Agency Activities \& Other European Activities in the Field of Rare Diseases, cit.

${ }^{79}$ EUROPEAN MEDICINES AGENCY. Special Topics - Medicines for rare diseases, cit.

${ }^{80}$ BRASIL. Lei $n^{\circ}$ 9.782, de 26 de janeiro de 1999. Define o Sistema Nacional de Vigilância Sanitária, cria a Agência Nacional de Vigilância Sanitária, e dá outras providências. Disponível em: <http://www.anvisa.gov. br/legis/consolidada/lei_9782_99pdf>. Acesso em: 08 set. 2012.

${ }^{81}$ BRASIL. Conselho Nacional de Saúde. Consulta Pública do Sistema Único de Saúde. Proposta de revisão da Resolução $n^{\circ}$ 196, de 10 de outubro de 1996. Brasília: CNS; 2012. Disponível em: <http:// 200.214.130.94/ consultapublica/display/dsp_print_completo.php?d=3228>. Acesso em: 18 out. 2012.
} 
questões éticas de estudos que envolvem seres humanos -, 88 itens foram apresentados para receber contribuições, que que totalizaram 1.849. Os usuários de serviços familiares, amigos e portadores da mucopolissacaridose apresentaram 44,4\% das 99 contribuições feitas para o item "Preâmbulos", manifestando-se a favor do início imediato de uma pesquisa sobre essa doença rara. Quanto ao ponto 31 da consulta - "Obrigação de o patrocinador continuar por tempo indeterminado a assistir ao paciente sujeito da pesquisa” -, 52,2\% das 267 contribuições se opuseram ao tópico, por considerarem que ele inviabilizaria a pesquisa referida no item ${ }^{82}$.

Sobre a participação no CNS, apurou-se que, no segmento "usuários”, das 27 cadeiras (nove titulares, nove primeiros suplentes e nove segundos suplentes) de portadores de patologias do plenário, atualizadas em dezembro de $2012^{83}$, duas são representações de entidades de portadores de doenças raras: a talassemia (Associação Brasileira de Talassemia - ABRASTA) e a esclerose múltipla (Movimento dos Portadores de Esclerose Múltipla - MOPEM), enfermidades que constam da lista atendida pelo $\mathrm{CEAF}^{84}$.

\section{Discussão}

Com base nos resultados obtidos, alguns pontos relevantes sobre a efetivação dos princípios da integralidade e universalidade no SUS devem ser desenvolvidos.

\section{Desafios jurídicos e institucionais para a efetivação da universalidade e da integralidade no sistema público de saúde no Brasil}

Os princípios da universalidade e da integralidade do SUS estão intimamente relacionados e essa relação é determinada pela maneira com que o Estado brasileiro decide sobre quais serviços e produtos serão oferecidos no âmbito do sistema público de saúde. As inovações trazidas pela Lei 12.401/2011 ainda não foram plenamente incorporadas ao sistema, gerando bastante expectativa com relação a sua contribuição para a melhoria do SUS e para a redução da judicialização da política de saúde no país. Para visualizar a tensão existente entre o novo modelo de definição da "integralidade" e o princípio da universalidade, imagine-se uma hipótese na qual o sistema público somente oferecerá de forma universal os serviços que constarem dos protocolos clínicos aprovados pelo Ministério da Saúde. Nesses casos,

${ }^{82}$ BUJDOSO, Yasmin Lilla Veronica. A construção da democracia sanitária em arenas de debate: o caso do Conselho Nacional de Saúde [Relatório de Pesquisa de Pós-Doutorado]. São Paulo, SP: Faculdade de Saúde Pública da Universidade de São Paulo, 2012.

${ }^{83}$ BRASIL. Ministério da Saúde. Portaria $n^{\circ} 2.814$, de 12 de dezembro de 2012. Designar os membros titulares, $1^{\circ}$ e $2^{\circ}$ suplentes, do Conselho Nacional de Saúde para o triênio 2012/2015. Disponível em: <http:// www.in.gov.br/visualiza/index.jsp?jornal=2 \&pagina=32\&data=13/12/2012>. Acesso em: 10. fev. 2013.

${ }^{84}$ BRASIL. Ministério da Saúde. Elenco de Referência Nacional do Componente Estratégico da Assistência Farmacêutica. Brasília, DF: Ministério da Saúde; 2012A. Disponível em: <http://portal.saude.gov.br/portal/ arquivos/pdf/medicamentos_insumos_componente_estrategico_RENAME.pdf.>. Acesso em: 02 jul. 2012. 
os pacientes com demandas que não estão contempladas pelos protocolos oficiais ficariam à margem do sistema público de saúde e teriam negados os seus pedidos de tratamento pelo poder público. Nessa hipótese, o princípio da integralidade deixa de ser cumprido, já que o SUS estará deixando de atender uma pessoa com necessidades comprovadas de saúde; também o princípio da universalidade estaria sendo violado, já que o não atendimento de uma pessoa, seja lá a razão levantada, caracteriza a discriminação no atendimento.

Vale ressaltar que a não conformação da necessidade de uma pessoa aos protocolos e diretrizes estabelecidos pelo poder público pode advir de diferentes fatores, tais como: efeitos colaterais violentos à medicação ou tratamento que constam da relação pública; doenças negligenciadas que não possuem protocolos ou diretrizes terapêuticas; doenças raras que, por sua raridade, também são negligenciadas e não possuem protocolos; ausência de resposta ao tratamento/medicamento indicado no protocolo, dentre outros.

Desde as suas discussões no Congresso Nacional, a busca pela definição dos contornos da diretriz da integralidade por meio de lei foi questionada no que se refere à sua constitucionalidade, à medida que se refere a um dispositivo constitucional. $M \operatorname{rrques}^{85}$, ainda à época da tramitação para aprovação legislativa, argumentou que:

ao reduzir o princípio constitucional de integralidade de assistência à saúde à oferta pública dos medicamentos, selecionados pelo gestor público, o presente projeto de lei representa um retrocesso em relação à garantia ampla dos direitos humanos, focada em princípios que permitem a garantia digna da saúde de todos.

A autora alertou, ainda, sobre os diversos problemas que perpassariam as políticas públicas de medicamentos, mencionando a "alegada falta de verbas" e o "atraso da revisão" da RENAME, e ainda as possíveis "falhas e demoras na atualização" dos protocolos e listas oficiais em adotar as novas tecnologias e recursos disponíveis.

A opção atual institucionalizada com a CONITEC, os PCDTs e as relações de serviços e medicamentos aposta, mais uma vez, na capacidade regulatória do Estado ao definir uma instância capaz de delimitar os contornos da integralidade, mediante garantia financeira do Estado, ao ampliar a população coberta e os agravos cobertos por meio da incorporação formal dos procedimentos e produtos claramente estabelecidos como eficazes, seguros e custo-efetivos em relação a suas alternativas.

A tensão entre integralidade e universalidade reside, em grande parte, nas relações entre a dimensão estatal e o mercado no âmbito de um cenário de economia emergente em que se ampliam os direitos sociais e se consolidam os direitos civis e políticos. Ou seja, em um ambiente em que se ampliam os gastos com saúde

\footnotetext{
${ }^{85}$ MARQUES, Silvia B. O princípio constitucional da integralidade de assistência à saúde e o projeto de lei $n$. 219/2007: interpretação e aplicabilidade pelo Poder Judiciário. Revista de Direito Sanitário, São Paulo, v. 10, n.2, out. 2009.
} 
é necessário não só combater a corrupção, como também ampliar os mecanismos de monitoramento, avaliação e responsabilização dos gestores e gerentes.

É ainda necessário que a relação entre Estado e mercado induza a um setor produtivo eficiente e capaz de satisfazer as necessidades da população do país. Essa relação deve promover o desenvolvimento social - assegurando a efetivação dos direitos e melhorando as condições de vida -, o desenvolvimento econômico potencializado pelo chamado Complexo Industrial da Saúde - e a consolidação das instituições públicas, em seus contornos democráticos, republicanos, federativos e quanto ao sistema de pesos e contrapesos entre os poderes do Estado.

À complexidade dessa realidade vêm somar os esforços de ampliação da governança das políticas públicas, com a ampliação da participação social, assim como a da globalização dos riscos à saúde e das instâncias de tomadas de decisão: não basta formular políticas voltadas para dentro, já que boa parte dos riscos são globais, nem pensar em resolver os problemas domésticos só com recursos intramuros, pois os atores sociais e econômicos costumeiramente são internacionais, ou transnacionais.

\section{Universalidade, integralidade e regulação estatal do sistema público de saúde}

No que se refere à função regulatória do Estado, há um amplo desafio a ser enfrentado, com relação aos custos crescentes para o sistema público de saúde, decorrentes dos anseios populacionais por tecnologias novas ou inovadoras oferecidas pelo mercado, nem sempre realmente necessárias, mas que costumeiramente chegam ao conhecimento da sociedade portando forte apelo propagandístico. Tecnologias caras que, eficazes ou não, têm sido acolhidas no país em nome do princípio da universalidade da cobertura, da diretriz da integralidade do tratamento e da especificidade do mercado da saúde, que opera um produto de valor monetário inestimável: a vida e a qualidade de vida. Tudo se justifica diante desses dois apelos. E assim frequentemente nos encontramos em meio a uma disputa entre o atendimento de um direito individual ou o atendimento de um direito coletivo.

Portanto, mais uma vez, o tema da tomada de decisão sobre quais tecnologias devem ser incorporadas ao sistema de saúde representa uma discussão sobre a própria viabilidade do sistema, bem como sobre a viabilidade de direitos universais. O ponto central da tomada de decisão passa a ser a definição sobre que tecnologias em saúde se constituem em direitos cujo acesso deve ser assegurado. Por acaso, toda e qualquer promessa de solução de um grave problema de saúde deve ser entendido como um direito? Qual o exato limite da ideia de integralidade constante da Constituição Federal?

Tecnologias da medicina convencional, da medicina tradicional ou das medicinas paralelas tomadas indistintamente poderão ser assim consideradas como direitos, uma vez que prometem a solução de problemas de saúde. E, nesse caso, 
caberá ao poder público - com recursos provenientes dos tributos, descontados a reserva da corrupção e da gestão equivocada - arcar com os custos da promessa. Esse argumento aborda o caso de tecnologias não comprovadamente eficazes. Entretanto, a tomada de decisão deverá lidar também com tecnologias eficazes, mas de menor custo-efetividade. Nesses casos, a tomada de decisão orientada tecnicamente poderá, mediante a elaboração de protocolos clínicos e organizacionais, lidar com o assunto, assegurando quem terá acesso a que tecnologia disponível e incorporada ao sistema?

A tomada de decisão sobre a incorporação tem outras duas dimensões a serem abordadas: identificação dos problemas que necessitam de solução e o reconhecimento público da decisão tomada. A primeira dimensão tem um claro componente democrático. Os setores que dispõem de mais recursos socioeconômicos são os que mais se beneficiam da proposição de incorporações e da segurança de acesso universal ao direito à saúde. Coloca-se a necessidade de que o Estado, em nome do bem público, equilibre o jogo de forças na sociedade, de modo que interesses sub-representados tenham igualdade de condições de propor e ter examinadas suas propostas de incorporação. Nessa dimensão se colocam tanto a questão da pressão dos diversos grupos de interesse em disputa quanto dos segmentos que carecem de força econômica e política para se colocarem nas arenas de disputa. A segunda dimensão diz respeito mais ao caráter republicano do Estado: decisões tomadas precisam ser efetivadas, como um respeito impessoal pelo bem público identificado. Os poderes de Estado devem executar, a partir da deliberação, sem lhe opor empecilhos; devem normatizar complementarmente a deliberação, sem a interpretar e transformar; e devem velar pelo cumprimento dessa execução, acatando imediatamente a deliberação.

\section{Lições extraídas da situação institucionalizada para o encaminhamento das doenças raras}

Considerando que a discussão sobre o princípio da universalidade e a diretriz de integralidade no SUS deve se dar não somente com base em discussões teóricas, mas principalmente orientada pelos efeitos concretos sobre a saúde de indivíduos, pessoas e coletividades, $o$ artigo ensejou discuti-los com base na problemática trazida pelas doenças raras e pelos medicamentos órfãos. Por mais desenvolvido que seja o sistema de incorporação de novas tecnologias no sistema público de saúde, sempre haverá exceções, casos especiais, necessidades diferenciadas, a exigir do Estado uma organização mais complexa e afinada com as demandas reais de saúde da população. O fortalecimento das instituições democráticas de participação no sistema de saúde é fundamental, à medida que essas instituições - conferências e conselhos de saúde, consultas e audiências públicas, dentre outras - é que garantem um ambiente mais ampliado de discussão, favorecendo decisões mais eficazes e legítimas por parte das autoridades públicas responsáveis. 
Também é importante registrar que os princípios da universalidade e a diretriz de integralidade exigem do Estado o atendimento de pessoas portadoras de doenças raras. No entanto, se restrições à inclusão ao sistema público de saúde do atendimento aos cidadãos portadores de doenças raras são o mesmo que negar o princípio da universalidade, é bastante razoável considerar que a organização de protocolos clínicos e diretrizes terapêuticas para incorporação ao sistema público é extremamente complexa e invariavelmente deixará o Estado em débito com a sociedade.

O tratamento de doenças raras está intimamente vinculado aos medicamentos órfãos e inclui todos os fármacos, próteses, agentes biológicos ou preparos dietéticos distintos destinados ao seu tratamento. Essas doenças são um conjunto heterogêneo de patologias, com prevalências e incidências bastante distintas, de menos raras (um para dois mil habitantes) até raríssimas (um para 1 milhão de habitantes), sendo ainda classificadas pela Orphanet em 32 grupos distintos ${ }^{86,87}, \mathrm{o}$ que requer um novo enfoque sociossanitário por parte dos sistemas de saúde, uma vez que seu tratamento é mais complexo e oneroso.

Uma política de atenção às doenças raras deveria ocorrer por meio de um conjunto de ações integradas com as distintas instâncias de governo e da sociedade civil a fim de fortalecer atores sociais e indivíduos no tratamento dessas enfermidades. Considerando que a intersetorialidade das ações de saúde é um dos princípios basilares do SUS, reforça a necessidade de se construir a política por meio de articulação, sinergia e integração das ações já desenvolvidas pelo Ministério da Saúde, como é o caso da Política Nacional de Genética Clínica, que abarca essas enfermidades, evitando-se sobreposições de ações. Deve considerar ainda as iniciativas da sociedade civil, de tal forma que seja legitimada socialmente por meio da criação de uma agenda integrada de saúde.

Para a efetiva implantação de uma política específica para doenças raras é necessário garantir sua consolidação política, financeira, institucional e operacional, legitimando-a pela atuação dos diversos fóruns de participação social, como os conselhos de saúde e as comissões intergestoras bipartite e tripartite. Os âmbitos decisórios nas três esferas de governo precisam ser povoados pela participação da sociedade civil, inclusive as associações de portadores de patologias, contribuindo para a implantação de uma política efetiva.

\footnotetext{
861 - cardíacas; 2 - anomalias de desenvolvimento durante a embriogênese; 3 - erros de metabolismo natos; 4 - gastroentereológicos; 5 - neurológicos; 6 - abdominais; 7 - hepáticos; 8 - torácicos; 9 - de pele; 10 - renais; 11 - oculares; 12 - endócrinos; 13 - hematológicos; 14 - imunológicos; 15 - sistêmicos; 16 - odontológicos; 17 - circulatórios; 18 - ósseos; 19 - otorrinolaringológicos; 20 - de infertilidade; 21 - tumores; 22 - infecciosas; 23 - intoxicações; 24 - ginecológicos, 25 - maxilo-faciais; 26 - psiquiátricos.; 27 - alérgicos; 28 - urogenitais; 29 - teratológicos; 30 - má formações cardíacas; 31 - respiratórios; 32 - genéticas. ${ }^{87}$ ORPHANET. Orphadata. Classification of Rare Diseases: hierarchical representation. Paris, France: Orphanet, 2012. Disponível em: <http://www.orphadata.org/cgi-bin/inc/product3.inc.php >. Acesso em: 13 jul. 2012.
} 
A questão do reduzido número de doenças raras atendidas é referida por inúmeros autores como um problema comum às doenças negligenciadas, em que são incluídas, juntamente com as doenças raras as doenças tropicais, prevalentes em países periféricos ${ }^{88,89,90}$. Nos países periféricos, a baixa capacidade financeira para aquisição de medicamentos desestimula a indústria farmacêutica a desenvolver tratamentos e medicamentos para as doenças tropicais, ao mesmo tempo em que as empresas recebem subsídios financeiros de órgãos de países centrais como OOPD e EMEA para desenvolverem produtos para o tratamento de doenças raras, aumentando as desigualdades de acesso a tratamento em nível global.

No Brasil, a Resolução da Diretoria Colegiada $16 / 2008^{91}$ da ANVISA diferencia doenças raras de doenças negligenciadas. No item II, refere doenças negligenciadas como aquelas que "não apresentam atrativos econômicos para o desenvolvimento de fármacos, por atingirem, predominantemente, a população dos países em desenvolvimento", enquanto as doenças raras ou órfãs são especificadas no item IV caracterizadas como "aquelas que afetam um pequeno número de pessoas quando comparado com a população geral”. Esses conceitos pouco contribuem para o avanço dos desafios a serem enfrentados pelo sistema público de saúde para a melhoria da assistência farmacêutica nesse campo pantanoso.

Nesse sentido, o exemplo das doenças raras recomenda que, inicialmente, o Estado brasileiro avance em seu desenvolvimento institucional e regulatório para oferecer aos portadores dessas doenças um atendimento que contemple os princípios da universalidade e da integralidade.

Além disso, vale destacar que, por mais que o Estado organize-se para fornecer um atendimento universal e integral aos cidadãos, sempre haverá exceções aos protocolos e diretrizes clínicas e terapêuticas incorporados ao sistema pela CONITEC e outras instâncias decisórias. O grande desafio, portanto, que vai para além das doenças raras e dos medicamentos órfãos, é conseguir organizar um sistema que ao mesmo tempo dê conta dos casos mais prevalentes na sociedade e dos casos raros ou que não se encaixam nos protocolos públicos, respeitando os princípios da universalidade e da integralidade.

\footnotetext{
${ }^{88}$ FARLOW, Andrew. A global medical research and development treaty. An answer to global health needs? London, UK: IPN Working Papers on Intellectual Property, Innovation and Health; 2007. Disponível em: <http://www.il-rs.org.br/ingles/arquivos/AGlobalMedical.pdf>. Acesso em: 01 jul. 2012.

${ }^{89}$ FEHR Angela; THÜRMANN, Petra; RAZUM, Oliver. Expert Delphi survey on research and development into drugs for neglected diseases. BMC Health Services Research, London, UK, v. 11, p.312-318, Nov. 2011.

${ }^{9}$ VILLA, Stefano; COMPAGNI, Amélia; Reich Michael R. Orphan Drug legislation: lessons for neglected tropical diseases. The International Journal of Health Planning and Management, Malden, MA, USA, v. 24, n. 1, p. 27-42, Jan./Mar. 2009.

${ }^{91}$ BRASIL. Ministério da Saúde. Agencia Nacional de Vigilância Sanitária. Resolução da Diretoria Colegiada $R D C n^{\circ} 16$, de 13 de março de 2008. Altera a Resolução $R D C n^{\circ} 28$, de 4 de abril de 2007, que dispõe sobre a priorização de análise técnica de petições no âmbito da Gerência Geral de Medicamentos da ANVISA. Disponivel em: <http://www.in.gov.br/ visualiza/index.jsp?jornal=1\&pagina=38\&data=17/03/2008>. Acesso em: 10 out. 2012.
} 


\section{Considerações finais}

O princípio da universalidade impõe ao Estado brasileiro um dever específico para cada necessidade de saúde identificada no território nacional, sendo vedada a discriminação por qualquer razão que seja. Já o princípio da integralidade impõe ao Estado o dever de oferecer aos cidadãos os serviços e produtos de saúde condizentes com as suas necessidades específicas, englobando serviços e ações de promoção, proteção e recuperação da saúde.

Sempre que o Estado não conseguir oferecer uma solução terapêutica a um cidadão, seja porque o serviço ou produto não foram ainda incorporados formalmente ao sistema, seja porque a necessidade da pessoa é especial e não se encaixa nos protocolos e diretrizes clínicas já fixados, caberá ao cidadão o direito de exigir do Estado, pela via administrativa ou judicial, o oferecimento de uma solução condizente.

Nesse sentido, muito embora a criação da CONITEC e os novos contornos dados ao conceito de integralidade pela Lei 12.401/2011 sejam avanços importantes que podem resultar em melhoria da eficácia e racionalidade do sistema público de saúde, é de se ressaltar que sempre haverá alguma exceção a exigir dos poderes executivo, legislativo e judiciário uma medida também de exceção a fim de garantir o direito à saúde de pessoas portadoras de doenças raras ou necessidades especiais que não se encaixam nos protocolos estatais. A judicialização da saúde é, em estados democráticos de direito, uma importante via de acesso a serviços e produtos que não estão incorporados ao sistema público de saúde, mas fundamentais para a proteção da vida e da saúde, mesmo quando não constam dos protocolos e diretrizes terapêuticas do Estado.

\section{Referências}

BRASIL. Ministério da Saúde. CONITEC, Secretaria de Ciência, Tecnologia e Insumos Estratégicos. Uso offlabel: erro ou necessidade? Revista de Saúde Pública, São Paulo, v. 46, n. 2, p. 395-397, 2012.

Ministério da Saúde. Portal da Saúde. Doenças raras. Brasília, DF: Ministério da Saúde; 2012. Disponível em: <http://www.brasil.gov.br/ sobre/saude/atendimento/doencasraras $>$. Acesso em: 01 out. 2012.

Ministério da Saúde. Portal da Saúde. Notícias. Doenças raras: Saúde ampliará ações de atenção aos pacientes. Brasília: MS; 2013. Disponível em: <http://portalsaude.saude.gov. br/portalsaude/noticia/5495/162/ministerio-ampliara-acoes-de-atencao-aos-pacientes.html >. Acesso em: 10 fev. 2013.

Ministério da Saúde. Secretaria de Ciência, Tecnologia e Insumos Estratégicos. Comissão Nacional de Incorporação de Tecnologias no Sistema Único de Saúde. Protocolos Clínicos, Propostas submetidas e Deliberações da antiga CITEC. Brasília, DF: CONITEC, 2012. Disponível em: <http://portal.saude.gov.br/portal/saude/Gestor/area.cfm?id_area=1611>. Acesso em: 01 out. 2012. 
Ministério da Saúde. Situações clínicas tratadas pelo Componente Especializado da Assistência Farmacêutica. Brasília, DF: Ministério da Saúde; 2012c. Disponível em: <http://portal. saude.gov.br/portal/arquivos/pdf/situacoes_clinicas_ceaf_jan_2012.pdf>. Acesso em:02 jul. 2012.

BUJDOSO, Yasmin Lilla Veronica. A construção da democracia sanitária em arenas de debate: o caso do Conselho Nacional de Saúde [Relatório de Pesquisa de Pós-Doutorado]. São Paulo, SP: Faculdade de Saúde Pública da Universidade de São Paulo, 2012.

CÂMARA DOS DEPUTADOS. Projeto de Lei no 7445 de 04 de junho de 2010. Altera a Lei $n^{\circ}$ 8.080, de 19 de setembro de 1990, para dispor sobre a assistência terapêutica e a incorporação de tecnologia em saúde no âmbito do Sistema Único de Saúde (SUS). Brasília, DF: Câmara dos Deputados; 2010. Disponível em: <http://www.camara.gov.br/ proposicoesWeb/prop_mos trarintegra? codteor=778285\&filename=Avulso $+-P L+7445 / 2010>$. Acesso em: 18 set. 2010.

CENTRO PAULISTA DE INVESTIGAÇÃO CLÍNICA - CEPIC. Conselho de Ética médica autoriza pesquisa para tratar doença rara. São Paulo, SP: CEPIC; 2012. Disponível em: <http:// www.cepic.com.br/blog/conselho-de-etica-medica-autoriza-pesquisa-para-tratar-doencarara >. Acesso em: 07 jul. 2012.

EUROPEAN MEDICINES AGENCY. Special Topics - Medicines for rare diseases. London: EMEA; 2012. Disponível em: <http://www.ema.europa.eu/ema/index.jsp?curl=pages/ special_topics/general/general_>. Acesso em: 01 jul. 2012.

EUROPEAN ORGANISATION FOR RARE DISEASES - EURODIS. About Rare Diseases. London: EURODIS; 2012. Disponível em: <http://www.eurordis.org/pt-pt/doencas-raras>. Acesso em: 09 jul. 2012.

EUROPEAN UNION COMMITTEE OF EXPERTS ON RARE DISEASES -EUCERD. 2012 EUCERD Report on the State of the Art of Rare Disease Activities in Europe - Part IV: European Medicines Agency Activities \& Other European Activities in the Field of Rare Diseases. Paris, France: European Union; 2012. Disponível em: <http://www.eucerd.eu/upload/file/ Reports/2012ReportStateofArt RDActivitiesIV.pdf>. Acesso em 12 fev. 2013.

FARLOW, Andrew. A global medical research and development treaty. An answer to global health needs? London, UK: IPN Working Papers on Intellectual Property, Innovation and Health; 2007. Disponível em: <http://www.il-rs.org.br/ingles/arquivos/AGlobalMedical. pdf>. Acesso em: 01 jul. 2012.

FEHR Angela; THÜRMANN, Petra; RAZUM, Oliver. Expert Delphi survey on research and development into drugs for neglected diseases. BMC Health Services Research, London, UK, v. 11, p.312-318, Nov. 2011.

GINSBURG, Geoffrey Steven et al. Implications of pharmacogenomics for drug development and clinical practice. Archives of Internal Medicine, Bethesda, MD, USA, v. 165, n. 20, p. 2331-2336, Nov. 2005.

HAFFNER, Marlene E. Focus on research: adopting orphan drugs - two dozen years of treating rare diseases. The New England Journal of Medicine, Massachusetts, NE, USA, v.354, n. 5, p. 445-447, 2006. 
LABSON, Michael S. Pediatric Priorities: Legislative and Regulatory Initiatives to Expand Research in Use of Medicine in Pediatric Patients. Journal of Health Care and Law Policy, Baltimore, MD, USA, v. 6, n. 34, p. 33-72, 2000.

MARQUES, Silvia B. O princípio constitucional da integralidade de assistência à saúde e o projeto de lei n. 219/2007: interpretação e aplicabilidade pelo Poder Judiciário. Revista de Direito Sanitário, São Paulo, v. 10, n.2, out. 2009.

MEDICINANET. Guia de Remédios. Disponível em: <http://www.medicinanet.com.br/ categorias/medicamentos.htm>. Acesso em: 01 jul. 2012.

MINISTÉRIO PÚBLICO FEDERAL. Procuradoria da República do Rio Grande do Sul - Núcleo de Saúde. Audiência pública para discussão de uma Política Nacional de Atenção Integral em Genética Clínica. Porto Alegre, RS: Ministério Público Federal; 2012. Disponível em: <http://www.prrs.mpf.gov.br/home/audiencias/genetica-clinica/ata_aud_geneticaclinica_11-06.pdf >. Acesso em: 12 jul. 2012.

MIRANDA, Jorge. Manual de direito constitucional. 2. ed. Coimbra: Coimbra Ed., 1998. t. 4.

NATIONAL ORGANIZATION FOR RARE DISORDERS - NORD. Rare Disease Information. Washington, DC, USA: NORD; 2012. Disponível em: <http://www.rarediseases.org/raredisease-information>. Acesso em: 08 jul. 2012.

OFFICE OF ORPHAN PRODUCTS DEVELOPMENT - OOPD. 2011 Report. Silver Spring, MD, USA: FDA; 2012. Disponível em: <http://www.fda.gov/downloads/AboutFDA/ ReportsManualsFormsReports/BudgetReports/UCM298358.pdf>. Acesso em: 14 jul. 2012.

OLIVEIRA, Cláudio Roberto; MELAMED, Clarice; MACHADO, Rejane. Políticas da 'expertise': doenças raras e gestão das tecnologias em saúde pelo SUS. Revista Brasileira de Ciência e Tecnologia e Sociedade, São Carlos, SP, v. 2, n. 2, p. 150-186, 2011.

ORPHANET. Orphadata. Classification of Rare Diseases: hierarchical representation. Paris, France: Orphanet, 2012. Disponível em: <http://www.orphadata.org/cgi-bin/inc/product3. inc.php >. Acesso em: 13 jul. 2012.

Rare Diseases and Orphan Drugs. Paris, France: Orphanet, 2012. Disponível em: $<$ http://www.orpha.net/consor/cgi-bin/>. Acesso em: 13 jul. 2012.

PARLAMENTO EUROPEU. Conselho Europeu. Regulamento (CE) no 141/2000 de 16 de Dezembro de 1999. Relativo aos medicamentos órfãos. JOL 18 de 22.1.2000, p. 1-5. Disponível em: $<$ http://eur-lex.europa.eu/Notice.do?val=237362:cs\&lang=pt\&list=237362:cs,\&pos=1\&pag $\mathrm{e}=1 \& \mathrm{nbl}=1$ \&pgs $=10 \&$ hwords $=\&$ checktexte $=$ checkbox\&visu=\#texte $>$. Acesso em: 10 jul. 2012 .

POLANCZYK, Carisi Anne; VANNI, Tazio; KUCHENBECKER, Ricardo de Souza. Avaliação de tecnologias em saúde no Brasil e no contexto internacional. In: NITA, Marcelo et al. Avaliação de tecnologias em saúde: evidencia clínica, análise econômica e análise de decisão. Porto Alegre: Artmed, 2010. p. 433-449. 
REIDENBERG, Marcus M. Are drugs for rare diseases "essential"? Bulletin of the World Health Organization, v.84, n. 9, p. 686, Sept. 2006.

STOLK, Pieter et al. "Rare essentials": drugs for rare diseases as essential medicines. Bulletin of the World Health Organization, v.84, n. 9, p. 745-751, Sept. 2006.

SUPREMO TRIBUNAL FEDERAL. Audiência Pública sobre Saúde. Brasília: Supremo Tribunal Federal; 2009. Disponível em: <http://www.stf.jus.br/portal/cms/vertexto.asp?servico=proce ssoaudienciapublicasaude $>$. Acesso em: 18 set. 2012.

UNITED STATES FOOD AND DRUG ADMINISTRATION - FDA. Developing Products for Rare Diseases \& Conditions. FDA, 2012. Disponível: <http://www.fda.gov/ForIndustry/ Developing Productsfor RareDiseasesConditions/default.htm>. Acesso em: 01 jun. 2012.

. The Orphan Drug Act (as amended) Code of Federal Regulations, Title 21, Revised as of April 1, 2004. Silver Spring, MD, USA: FDA, 2012. Disponível em: <http://www. fda.gov/RegulatoryInformation/Legislation/FederalFoodDrugandCosmeticActFDCAct/ SignificantAmendmentstotheFDCAct/OrphanDrugAct/default.htm>. Acesso em: 01 jun. 2012.

VILLA, Stefano; COMPAGNI, Amélia; Reich Michael R. Orphan Drug legislation: lessons for neglected tropical diseases. The International Journal of Health Planning and Management, Malden, MA, USA, v. 24, n. 1, p. 27-42, Jan./Mar. 2009

Fernando Aith - Professor Doutor do Departamento de Medicina Preventiva da Faculdade de Medicina da Universidade de São Paulo; Pesquisador e membro do Conselho Deliberativo do Núcleo de Pesquisa em Direito Sanitário da Universidade de São Paulo. Advogado. São Paulo/SP, Brasil.E-mail: fernando.aith@usp.br.

Yasmim Bujdoso - Pós-Doutoranda da Faculdade de Saúde Pública da Universidade de São Paulo; Pesquisadora do Núcleo de Pesquisa em Direito Sanitário da Universidade de São Paulo. São Paulo/SP, Brasil.

Paulo Roberto do Nascimento - Doutor em Saúde Pública; Pesquisador do Núcleo de Pesquisa em Direito Sanitário da Universidade de São Paulo. São Paulo/SP, Brasil.

Sueli Gandolfi Dallari - Professora Titular da Faculdade de Saúde Pública da USP; Coordenadora Científica do Núcleo de Pesquisa em Direito Sanitário da Universidade de São Paulo. Advogada. São Paulo/SP, Brasil. 